\title{
Habilitation in practice
}

In a recent conversation, Charles and I agreed that perception of symptoms was more important than severity of disease in determining disability. $\mathrm{He}$ suggested that, particularly with the mild and moderate diseases of old age, we needed an habilitator rather than a rehabilitator. When we next met for a round of golf together, the pair ahead included Alan G.

'Alan makes our point about habilitation,' Charles remarked.

'How come?' I said. 'He insists on smoking 20 cigarettes a day!'

'Would you expect a man with spirometry a third of normal to enjoy a game and walk round without difficulty?' he asked.

'Good lord, no!'

'That's what he tells me it is and yet there he is keeping well ahead of us. From the start of his breathlessness his wise old GP told him to get on with it and live a full life. Although he resented this at first, and nearly fell out with him, he now recognises what sound advice it was.'

'Charles, are you suggesting that if only the GPs would say a few firm words at the beginning, all these problems would be solved as simply and cheaply as that?'

'Not quite,' he said. 'I was only holding him up as an example of what can be achieved. The critical time was several years ago, when he was receptive. Things are not so easy now.'

'Why do you say that?'

'There can be too much pressure for doctors to be nice to patients. The temptation must be to tell them what they want to hear and, with the open access to medical records, not to make harsh judgements that are necessary for proper management. It is much easier to tell someone he is coping well but should take it easy, implying that he has got a serious disease, rather than to explain the truthful opposite and risk being misunderstood. Short-term contentment is bought at the price of long-term ill health'.
'How would you solve it, Charles?'

'We need both a medical and social approach.'

'Expand on the medical side first,' I suggested.

'I accept that there is another side to the evolution, or indeed the revolution, in the relationship between doctor and patient, or should I say customer? There is also virtue in the new found empathy which necessarily blurs to a certain extent the roles of doctor and nurse. This makes it extremely difficult to maintain the modern relationship between doctor and patient if the prime, and directly responsible, physician - the GP - has to make harsh judgements. An early independent assessment by an habilitator with the help of a symptomatologist concentrating on symptoms, rather than the impossible cure, would solve the problem. They would set the action plan which the GP and patient would implement.'

'That means everyone in the early stages of chronic disease would need referral. Wouldn't that be prohibitively expensive?'

'Sufficient demand and detachment might be possible within a large group practice to do it "in house".'

'And would this be before assessment in hospital by a specialist to exclude uncommon, serious treatable diseases?'

'Yes! You may not like this answer, which may seem to go against the principle of knowing your enemy before attempting treatment, but it has always been the mark of a good GP to recognise serious disease even if he does not know what it is. He should also be able to suggest an action plan for the most likely problem, explaining to the patient that no harm will come if the diagnosis proves to be more abstruse?

He reflected: 'But these are not the real points, Coe! What matters is whether there would be a net reduction in suffering and in cost.'

'Which is where our last conversation ended,' I reminded him and continued, 'We are agreed that cure and prevention of premature serious disease 
inevitably leads to increased demand on resources in the long

run. In what way is this different?'

'It might seem paradoxical that we are hopeful of reducing cost by accepting illness more readily, but we are concentrating on reducing its impact. This requires a substantial reduction of resources required for management of the current illness and, because the patient is fitter, those needed for subsequent problems.'

'But if the patient lives longer as a result?'

'Fair point! But if one looks at it terms of cost per healthy life years gained, rather than global cost then I am sure it's a potential bargain!'

'I am still not convinced that medical resources really would be released.'

'But there are huge potential savings in social costs, in terms of claims for disability, provided that the major problem is faced.'

'What's that, Charles?'

'There is reluctance to ascribe blame to the "customer" for deconditioning - the consequence of not availing himself of the habilitation offered. All the pressures on those responsible for payments are to accept the claimant as he says he is, irrespective of the manifest disease; hence the increase in disability payments. One might say that now it is rough justice to society, as doctors and others often manage early disease so badly. If there was a proper habilitation service available to all and this help was declined or no real effort made, then the excuse would no longer be valid. In the future, would the adjudicating officers and the appeal tribunals have the courage to require a determined effort on the part of the claimant before allowing long-term benefit?'

'Why not now?'

'I am sure they should do so to a greater extent than at present, but they perceive it as difficult in these days of human rights and client autonomy. Even today, where deconditioning is recognised, the diagnosis should be stated and the payment limited to a reasonable period, to allow time for rehabilitation. This might have a major impact.'

I am not sure which way the finances would work out. Come what may, the potential benefits to the individual are obvious but habilitation could only work financially in a climate where disability payments are to be kept in control. This means that the problem of ensuring that those with objectively mild disease and deconditioning do accept some responsibility and take the consequences must be addressed. 